Angelo Brandelli Costa

Universidade Federal do Rio Grande do Sul (UFRGS)

Henrique Caetano Nardi

Universidade Federal do Rio Grande do Sul (UFRGS)

\title{
O casamento "homoafetivo" e a política da sexualidade: implicações do afeto como justificativa das uniões de pessoas do mesmo sexo
}

\begin{abstract}
Resumo: No Brasil, as justificativas jurídicas para a realização de uniões entre pessoas do mesmo sexo estão assentadas no aspecto afetivo das relações com o uso do termo "homoafetividade". O objetivo deste estudo é questionar essas justificativas, apontando para as suas repercussões políticas e subjetivas. Os argumentos foram examinados a partir de uma análise de discurso foucaultiana e confrontados com o debate sobre o direto democrático à sexualidade no contexto político e social brasileiro contemporâneo. A análise indica que o Estado está legislando modelos de afeto em vez de garantir um direito democrático da sexualidade, ou seja, usando o discurso do amor romântico e produzindo, mesmo que implicitamente, um quadro regulamentar para as subjetividades com base em demandas particulares. A conclusão apresenta a necessidade de uma justificativa sustentada nos direitos fundamentais (liberdade, igualdade, não-discriminação), os quais, uma vez garantidos, permitiriam que uma esfera pública, laica, formal, universal e abstrata, possa atender aos interesses dos indivíduos, inclusive àqueles baseados no amor romântico, sem ser reduzida a ele. Palavras-chave: homoafetividade; homossexualidade; direitos humanos; casamento; união civil.
\end{abstract}

Copyright () 2015 by Revista Estudos Feministas.
"Em amor, quando a própria pessoa decide, as possibilidades de ventura são bem problemáticas. E, quando terceiros interferem e resolvem, as possibilidades se reduzem

a zero."

Nelson Rodrigues. Não se pode amar e ser feliz ao mesmo 
1 SUPREMO TRIBUNAL FEDERAL, 2011.

${ }^{2}$ Maria Berenice DIAS, 2000, p. 1 26.

\section{Introdução}

No dia 5 de maio de 2011 , o Supremo Tribunal Federal (STF) julgou favoravelmente a Ação Direta de Inconstitucionalidade (ADI) 4277 e a Arguição de Descumprimento de Preceito Fundamental (ADPF) 132,' que equipararam as uniões de pessoas de mesmo sexo às uniões entre pessoas de sexos diferentes. Em 2013, o Conselho Nacional de Justiça (CNJ) aprovou a resolução que obriga os cartórios de todo o país a celebrar o casamento civil e converter a união estável em casamento. Não há dúvida de que essa foi uma conquista sem precedentes para a garantia dos direitos às populações LGBT brasileiras. No entanto, no Brasil, ocorre um fenômeno peculiar: as justificativas para a efetivação desse direito justificativas que vêm tanto por parte dos juristas, inclusive ministros do STF, quanto por parte de uma parcela dos movimentos organizados da sociedade civil - estão calcadas em ideias de afeto e amor.

No Brasil e, ao que parece, em nenhum outro lugar no mundo, utiliza-se o termo homoafetividade - inclusive em documentos oficiais - para designar as relações entre pessoas do mesmo sexo, pretendendo-se, assim, legitimar direitos através da afirmação jurídica de um sentimento positivado. Somado a isso, o movimento LGBT majoritário luta pelo "direito de amar", reduzindo impasses políicos ao problema de afetos específicos, idealizados, com os quais nem todos os indivíduos se identificam e que não são passíveis de validade em uma esfera propriamente pública.

O termo homoafetividade foi cunhado pela jurista Maria Berenice Dias, em torno de argumentos como: "não é possível falar em homossexualidade sem falar em afeto" e "as uniões de pessoas do mesmo sexo nada mais são do que vínculos de afetividade". ${ }^{2}$ A noção de homoafetividade é bastante aceita e pouco questionada. Tudo se passa como se houvesse consenso sobre o que são afetos e sobre o que caracteriza uma relação conjugal. Ela é aplicada como modelo universal, sugerindo um ideal normativo que pode não contemplar todas as possibilidades da experiência conjugal, podendo inclusive servir de matriz para algumas formas de sofrimento.

Nosso objetivo é questionar a escolha do afeto e não de outra justificativa para o reconhecimento das unióes (e agora casamentos) de pessoas do mesmo sexo. Não precisaremos a definição de afeto ou discutiremos a natureza dos relacionamentos homossexuais, se eles se baseiam em afetos ou não. Estamos preocupados, especificamente, com as implicações subjetivas e políticas do uso da justificativa afetiva para a regulamentação das uniões de pessoas do mesmo sexo no Brasil. 
${ }^{3}$ Michel FOUCAULT, 1969.

${ }^{4}$ Marianne JØRGENSEN e Louise PHILLIPS, 2002.

${ }^{5}$ FOUCAULT, 1994a, p. 725.
6 FOUCAULT, 1994b, p. 158 tradução nossa.

${ }^{7}$ No livro L'archéologie du savoir Foucault utiliza o conceito de formações discursivas e não regimes de verdade, termo que surge posteriormente na sua obra. Entretanto, para nossa discussão o que interessa é pensar os efeitos de verdade dos discursos, assim, trabalhamos aqui com a forma pela qual rede de enunciados estrutura-se em regimes de verdade, próprios a um contexto específico.

8 JøRGENSEN e PHILLIPS, 2002.

\footnotetext{
9 DIAS, 2000, 2011

10 SUPREMO TRIBUNAL FEDERAL, 2011 .
}

\footnotetext{
11 Hannah ARENDT, 1962, 2004.

12 Sérgio Buarque de HOLANDA, 2012.

${ }^{13}$ Roger Raupp RIOS, 2006.

${ }^{14}$ Didier FASSIN, 2012.
}

A discussão que propomos será amparada na análise do discurso a partir das contribuições de Michel Foucault, desenvolvidas principalmente em sua obra L'archéologie du savoir (Arqueologia do saber). ${ }^{3}$ Louise Phillips e Marianne Jørgensen ${ }^{4}$ sistematizaram tal perspectiva, denominando-a análise do discurso crítica. Nessa abordagem, os saberes são compreendidos como produto dos regimes de verdade, ${ }^{5}$ os quais se referem à forma como um enunciado torna-se legítimo, adquire efeito e se estrutura no interior de um regime de verdade:

Cada sociedade tem seu regime de verdade, sua política geral da verdade: ou seja, os tipos de discursos que ela acolhe e faz funcionar como verdadeiros; os mecanismos e as instâncias que permitem distinguir os enunciados verdadeiros e falsos, a maneira como se sancionam esses e aqueles; as técnicas e os procedimentos que são valorizados para a obtenção de uma verdade; o estatuto daqueles que são encarregados de dizer aquilo que funciona como verdade. ${ }^{6}$

O objetivo do analista do discurso é, portanto, descrever a estrutura dos diferentes regimes, ${ }^{7}$ isto é, as regras do que pode e do que não pode ser dito e do que é considerado verdadeiro. Assim, embora tenhamos, em princípio, um número infinito de maneiras de formular enunciados, o ponto de partida desta análise são as afirmações que se apresentam de forma semelhante, recorrentes e associadas a um determinado regime de verdade, no interior do qual fazem sentido. Existem, assim, inúmeros enunciados que nunca são pronunciados, nunca seriam aceito como verdadeiros. São os regramentos sociais, históricos e políticos que delimitam o que é possível enunciar em dado contexto. O discurso é entendido então como conjuntos de enunciados que impõem limites para sua inteligibilidade. ${ }^{8}$

Para comentaristas de Foucault, a análise do discurso crítica privilegia as contingências que fazem com que um discurso específico seja enunciado com efeito de verdade e não outro.

Na presente discussão, o corpus de análise é constituído pelos seguintes materiais: a definição de homoafetividade a partir da obra de juristas afins a Dias, ${ }^{9}$ os votos dos ministros do Supremo Tribunal Federal, ${ }^{10}$ argumentos da corrente majoritária do movimento LGBT brasileiro na reivindicação do direito de amar. Como forma de debater o uso do afeto para legitimação de direitos, traremos as contribuições de Hannah Arendt quando discute o caráter antipolítico dos afetos, ${ }^{11}$ o conceito de cordialidade como marcador da cultura brasileira, ${ }^{12}$ a ideia de um direito democrático da sexualidade, ${ }^{13}$ e, por fim, a discussão da razão humanitária apontada por Didier Fassin. ${ }^{14}$ 
${ }^{15}$ DIAS, 2000.
${ }^{16}$ DIAS, 2011.

17 Paulo Roberto lotti VECCHIATTI, 2013 , p. 53.

${ }^{18}$ VECCHIATTI, 2013, p. 57

${ }^{19}$ DIAS [s.d.a]

${ }^{20}$ DIAS [s.d.b]

${ }^{21}$ BRASIL, 2002.

${ }^{22}$ VECCHIATTI, 2013, p. 273.

\section{O casamento homoafetivo e o casamento homossexual}

A ideia de homoafetividade foi consagrada pela jurista Maria Berenice Dias em sua obra União homossexual: o preconceito e a justiça..$^{15}$ O termo é aí apresentado, mas não elaborado. O que acontece na sequência é o seu desenvolvimento nas reedições de sua obra, ${ }^{16} \mathrm{em}$ diversos artigos seus e de outros juristas ligados ao direito de família; o Manual da homoafetividade parece sumarizar essa perspectiva:

A referida terminologia foi criada para justificar a inclusão das uniões entre pessoas do mesmo sexo no âmbito de proteção dos regimes jurídicos da união estável e do casamento civil, e com o intuito de se destacar que as uniões entre pessoas do mesmo sexo são pautadas no mesmo afeto romântico que justifica as uniões entre pessoas de sexo opostos. Isso foi feito por conta do preconceito social que afirmava que as uniões entre pessoas do mesmo sexo seriam motivadas por mera luxúria ou puro desejo erótico e não pelo sentimento de amor sublime que une duas pessoas de sexo oposto. ${ }^{17}$

A noção de homoafetividade viria na esteira da evolução da família no direito brasileiro. A Constituição de 1988 e o novo Código Civil teriam relativizado as justificativas clássicas para o reconhecimento de entidades familiares: os laços sanguíneos e os contratos. Enquanto o casamento civil é fundamentalmente um contrato, o qual é a prova de sua existência, o mesmo parecia aplicar-se à união estável entre pessoas de sexos diferentes. A união de pessoas do mesmo sexo, todavia, exigiu uma justificativa adicional, já que sua legitimidade social não era evidente. O afeto então é positivado como fundamento implícito, estendido retroativamente a todas as formas familiares, quando se diz que "a família contemporânea é caracterizada pela afetividade". ${ }^{18}$ Surge nessa esteira a família homoafetiva, ${ }^{19}$ coroando esse "novo" direito. ${ }^{20}$

O direito homoafetivo busca localizar o seu fundamento, o afeto, no texto jurídico e na própria definição do que é uma família. Isso fica claro, por exemplo, no que tem sido chamado de "princípio da afetividade do Código Civil Brasileiro e da Constituição". O artigo 1.723 do Código reconhece "como entidade familiar a união estável entre o homem e a mulher, configurada na convivência pública, contínua e duradoura e estabelecida com o objetivo de constituição de família". ${ }^{21}$ No entanto, interpreta-se esse artigo como se afirmasse que a entidade familiar se configura "no amor romântico que vise a uma comunhão plena de vida e interesses de forma pública, continua e duradora". ${ }^{22}$ Outros exemplos são afirmações como: "deve-se ter em mente que o amor familiar entre os envolvidos é o principal elemento a ser considerado

140 Estudos Feministas, Florianópolis, 23(1): 137-150, janeiro-abril/2015 
${ }^{23}$ VECCHIATTI, 2013, p. 169.

${ }^{24}$ VECCHIATTI, 2013, p. 168.

${ }^{25}$ SUPREMO TRIBUNAL FEDERAL, 2011 , p. 671.

${ }^{26}$ SUPREMO TRIBUNAL FEDERAL, 2011 , p. 629-630.

${ }^{27}$ Disponível em: http://www.abglt. org.br/docs/ManualdeComunica caoLGBT.pdf. Acesso em: 30 mar. 2013.

${ }^{28}$ Disponível em: http://juntos.org. br/201 1/10/pelo-direito-de-amar/. Acesso em: 31 mar. 2013.

29 INSTITUTO BRASILEIRO DE GEOGRAFIA E ESTATÍSTICA, 2012.

${ }^{30}$ Maria Angela D'INCAO, 1989 MINISTÉRIO DA SAÚDE, 2011; Anna Paula UZIEL, Luiz MELLO e Miriam GROSSI, 2006; e Elizabeth ZAMBRANO, 2006.

${ }^{31}$ Salvador MINUCHIN, 1982, p. 57.

${ }^{32}$ Ironicamente, se olharmos para a retórica de defensores da homoafetividade e para a de setores mais conservadores da sociedade brasileira, como neopentecostais (contrários aos direitos de homossexuais), as semelhanças são óbvias.

${ }^{33}$ Ryan CONRAD, 2010. quando se visa ao reconhecimento de uma relação". ${ }^{23} \mathrm{Ou}$ ainda, "tem-se que a afetividade está na gênese das relações familiares devendo-se garantir proteção às diversas formas e entidades familiares baseadas no afeto [...] visto que o ponto comum entre todas as famílias contemporâneas é o amor". ${ }^{24}$

Tal posição foi consolidada no julgamento favorável pelo STF da Arguição de Descumprimento de Preceito Fundamental 132 e da Ação Direta de Inconstitucionalidade 4277. Os votos dos ministros ancoraram-se especialmente em argumentos afetivos, como o do ministro Luiz Fux, "o que faz uma família é, sobretudo, o amor - não a mera afeição entre os indivíduos, mas o verdadeiro amor familiar" 25 e o do ministro relator Ayres Britto, que elege o termo homoafetividade para identificar o vínculo entre os pares do mesmo sexo. ${ }^{26}$ Da mesma forma, o segmento majoritário do movimento social LGBT adotou a perspectiva afetiva. Tomem-se como exemplo a Associação Brasileira de Lésbicas, Gays, Bissexuais, Travestis e Transexuais (ABGLT) que incorpora a perspectiva homoafetiva em sua pauta ${ }^{27}$ e o movimento "Juntos pelo direito de amar", que confunde casamento e amor, equiparando o direito de se casar ao direito de amar. ${ }^{28}$

Desde os anos 1960 e 1970, com a revolução sexual, a vida de heterossexuais tornou-se mais próxima aos modos de vida usualmente atribuídos a homossexuais. Ser heterossexual já não significa engajar-se ainda jovem em um relacionamento monogâmico sancionado pelo Estado, caracterizado pela presença de filhos, nitidamente delimitado pelo amor romântico e com duração para toda vida. ${ }^{29} \mathrm{Em}$ vez disso, há uma série de relações íntimas que podem ou não acompanhar a retórica do amor: do sexo casual anônimo, passando pelo poliamor. ${ }^{30} \mathrm{O}$ próprio conceito de família utilizado na psicologia contemporânea é mais abrangente, afastando-se do modelo baseado apenas em parentesco, coabitação ou afetividade: "Uma família é um sistema que opera através de padrões transacionais, isto é, de regras oriundas das interações repetidas entre os indivíduos". ${ }^{31}$ Então, como é que o amor romântico, uma ideia que o movimento LGBT no passado ajudou a desmitificar, torna-se apelo desse grupo ao Estado? ${ }^{32}$

Cabe lembrar que a luta em torno da formalização das uniões entre pessoas do mesmo sexo não é um ponto pacífico no movimento LGBT. Ela contrapõe um movimento que busca modificar a estrutura da sociedade a partir de suas experiências e outro que luta para aceitação (geralmente a qualquer custo). O primeiro segmento opõe-se à ideia de casamento em moldes heterossexuais como uma solução, lutando pela institucionalização de outras formas de relação. ${ }^{33}$ Já o segundo, almeja o reconhecimento dos direitos já garantidos a heterossexuais, como o do casamento. Acre- 
${ }^{34}$ VECCHIATTI, 2013.

${ }^{35}$ RIOS, 2013.

${ }^{36}$ FASSIN, 2012.

${ }^{37}$ Robert CASTEL, 2011.

${ }^{38}$ Steven PINKER, 1994.

39 Brian MCCABE e Jennifer HEERWIG, 2012. ditamos que tal garantia de direitos é legítima, sua justificativa, no entanto, não o é.

O primeiro argumento a favor do emprego do neologismo homoafetividade parece ser o da facilidade de sua aceitação com a redução do preconceito, uma vez que tal construção excluiria o desejo erótico exacerbado ou perverso, colado ao estereótipo da homossexualidade. ${ }^{34}$ Roger Raupp Rios $^{35}$ chama esse fenômeno de assimilacionismo familista: situar o afeto como identificador dos vínculos familiares, servindo como um mecanismo de anulação de práticas sexuais heterodoxas, sob a cláusula da pureza dos sentimentos. Em escala global, esse fenômeno tem sido chamado de razão

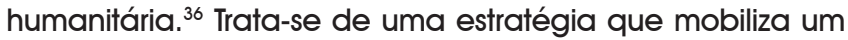
repertório discursivo moral de forma a justificar intervenções em torno de grandes questões sociais. A retórica das desigualdades de direitos apresenta os afetos como motor da ação social; problemas sociais são reinterpretados a partir da psicologia individual, a violência política é requalificada como trauma psicológico; o entendimento político da situação social é trocado por uma resposta emocional dirigida a vítimas não politizadas. Na confluência desse mecanismo, o argumento do afeto remete a uma forma de governo pela psicologia, como alerta Robert Castel, ${ }^{37}$ ao se referir à maneira como questões políticas são individualizadas na dinâmica da governamentalidade contemporânea.

Steven Pinke ${ }^{38}$ descreve o uso que fazemos de formas eufemísticas, revestidas de um senso de politicamente correto, para nos referirmos a fenômenos que disparam preconceitos. Ele traz o exemplo, na língua inglesa, em que water closet se tornou toilet, que se tornou bathroom, que então virou restroom e agora lavatory. Ou seja, a nova palavra rapidamente foi contaminada pelo preconceito, necessitando de uma nova versão eufemística. Pinker refere-se a esse fenômeno como esteira de eufemismo (euphemism treadmill), para mostrar que são os conceitos (discursos) e não as palavras que formam o núcleo do preconceito. Ele sugere que preconceito resiste a figuras retóricas frágeis, por estar enraizado em processos sociais complexos. De fato, uma pesquisa no contexto norteamericano não encontrou diferenças na aceitação das uniões entre pessoas do mesmo sexo ao utilizar diferentes formulações do termo, tidas como mais e menos aceitáveis socialmente. A percentagem de participantes que informaram apoio ao casamento e às uniões civis não se alterou significativamente quando o experimento alternou a pergunta usando as expressões "homossexuais", "gays e lésbicas" e "pessoas do mesmo sexo". ${ }^{39}$

O mesmo parece acontecer no contexto brasileiro. Apesar do deslocamento de sentido que a palavra homoafetividade sugere, se retomamos a análise discursiva proposta

142 Estudos Feministas, Florianópolis, 23(1): 137-150, janeiro-abril/2015 
40 Débora MASSMANN, 2012.

${ }^{41}$ Angelo Brandelli COSTA, Rodrigo PERONI, Denise BANDEIRA Henrique NARDI, 2013.

por Débora Massmann, ${ }^{40} \mathrm{a}$ sociedade brasileira ainda é refém do preconceito. ${ }^{41} \mathrm{O}$ uso da homoafetividade sugere que esse tipo de relação (casamento) ainda não adquiriu plena cidadania, apesar do ordenamento jurídico, precisando ainda de formas eufemísticas, endereçando o preconceito e a discriminação somente no nível do sintoma, usando-se o jargão psicanalííico. A redução do preconceito que a homoafetividade supostamente provocaria não ocorre. De nada adianta a mudança terminológica se não é acompanhada de transformação na estrutura que não permite que certas coisas sejam ditas. Pensar que a ação política (a ação que rearranja as estruturas sociais) é um mero manejo de palavras é, no mínimo, ingênuo.

Tomamos como exemplo a escassez de referências à noção de heteroafetividade. O contraponto à homoafetividade, na opinião pública, é a heterossexualidade e não a heteroafetividade..$^{42}$ A reforma da Constituição e posteriormente a do Código Civil, com o surgimento da figura da união estável, não exigiu o surgimento da heteroafetividade para qualificar esse tipo de relação. Para uniões entre pessoas de sexos diferentes, a ideia da "convivência pública, contínua e duradoura e estabelecida com o objetivo de constituição de família"43 foi suficiente. Foram as pessoas do mesmo sexo que exigiram que o amor romântico fosse acrescentado a essa lista, através do esforço hermenêutico do princípio da afetividade. Portanto, foi a forma encontrada para justificar o reconhecimento legal das uniões de pessoas do mesmo sexo que fez com que o nexo homoafetividade tivesse de ser criado. Algo similar ocorreu com a noção de homossexualidade, que surgiu no século XIX antes do construto heterossexualidade, para qualificar o desvio de uma norma implícita e socialmente aceitável. ${ }^{44}$ Ao que parece, homossexuais só podem entrar na so-

${ }^{44}$ Jonathan Ned KATZ, 1996.

\author{
${ }^{45}$ Judith BUTLER, 2004. \\ ${ }^{46}$ John AUSTIN, 1975. \\ ${ }^{47}$ Gayle RUBIN, 1984. \\ ${ }^{48}$ Michael WARNER, 1993.
}

${ }^{49}$ FOUCAULT, 1998. ciedade contemporânea quando comprovado que também são capazes de criar uma família, com base no afeto. Portanto, a entrada da homossexualidade no ordenamento jurídico está se dando por um processo de polimento moral. É importante lembrar que as lutas contra formas de assujeitamento podem produzir outros assujeitamentos. ${ }^{45} \mathrm{O}$ caráter performativo do enunciado ${ }^{46}$ da homoafetividade cria seu oposto, ou seja, o não-homoafetivo, reproduzindo as hierarquias do sexo já apontadas por Gayle Rubin. ${ }^{47}$ A heteronormatividade ${ }^{48}$ mantém-se operante a partir da criação de uma norma irmã, a homonormatividade, designando as formas socialmente mais legítimas de exercício da sexualidade não-heterossexual. Um paralelo pode ser traçado à relação que a burguesia estabeleceu com a sexualidade nos séculos XVIII e XIX. Foucault ${ }^{49}$ indica uma mudança na forma de legitimação das dominações, uma vez que a partir desses séculos ocorre uma inversão de importância entre o dispositivo da 
${ }^{50}$ FOUCAULT, 1998, p. 117

${ }^{51}$ FOUCAULT, 1994c, p. 227.

52 James Baldwin (1924-1987) fol um americano militante pelos direitos raciais e sexuais que acreditava que 0 amor seria 0 motor das revoluções sociais. Esta carta de Hannah Arendt é uma resposta ao ensaio Letter from a Region of My Mind, publicado em

17 novembro de 1962, na revista The New Yorker. aliança e o dispositivo da sexualidade. Até aquele momento a aristocracia legitimava a distinção e a dominação de classe na forma de laços sanguíneos, do valor das descendências e das alianças construídas a partir delas. A burguesia nascente, não dispondo desses expedientes, reivindicava tal distinção através de tecnologias voltadas ao controle e à produção de uma sexualidade tida como normal e saudável. Isso se deu na confluência dos discursos científico e jurídico que visavam a regulação da sexualidade. Nesse contexto, a heterossexualidade foi considerada norma e outras práticas sexuais, especialmente a homossexualidade, desvio. Por isso Foucault afirma que "o 'sangue' da burguesia foi seu próprio sexo". 50 Na esteira desse teórico, podemos afirmar que a afetividade hoje assume a função que o "sexo" teve para a burguesia e o "sangue", para a aristocracia. A sexualidade como dispositivo políico parece dar lugar ao que chamamos aqui "dispositivo da afetividade", regulador de formas de sexualidade não-heterossexual. Esse dispositivo se sustentaria em estruturas discursivas, sobretudo psicológicas e legais, criadas para fortalecer determinada hierarquia sexual. Vemos essa operação, por exemplo, quando emerge, nos textos referidos anteriormente, a Constitução e o Código Civil, uma cláusula afetiva não explicitada no texto legal.

O risco da estratégia que reforma o enunciado do afeto e evoca o amor romântico como modo de legitimação de direitos vai na direção contrária ao alerta de Foucault em relação às formas de reconhecimento e seu aprisionamento potencial. Ignora que as identidades são fruto de enunciados produzidos e oferecidos por determinada cultura e que criam o campo do possível à experiência de si:

Essa forma de poder que se exerce sobre a vida cotidiana imediata, que classifica os indivíduos em categorias, que os designa por sua individualidade própria, que os ata à sua identidade, os impõe uma lei (regime) de verdade que deve ser reconhecida por eles e que os outros devem reconhecer neles [...] um sujeito atado a sua própria identidade pela consciência e conhecimento de si. ${ }^{51}$

O movimento LGBT dominante usa a ideia de homoafetividade de forma estratégica, mas tem afirmado com clamor crescente a necessidade de reconhecimento desse afeto. Nossa crítica não recai na legitimidade das relações baseadas no amor romântico, mas no fato de que a noção de homoafetividade pode perpetuar as desigualdades que pretende resolver. Em resposta a um artigo publicado por James Baldwin, ${ }^{52}$ Hannah Arendt adverte-nos de forma semelhante, afirmando que "na política, o amor é um estranho, e quando nela se intromete nada pode ser alcançado, 
${ }^{53}$ ARENDT, 1962.

${ }^{54}$ ARENDT, 2004, p. 272.

${ }^{55}$ RIOS, 2006, p. 88.

${ }^{56}$ HOLANDA, 2012, p. 55. exceto hipocrisia". ${ }^{53}$ Arendt parece dizer que sob o pretexto do amor corremos o risco de despolitizar o debate, restringindoo a modos de viver que estão longe de serem universais. Esse ponto fica mais explicitado em seu debate em torno do casamento inter-racial nos Estados Unidos:

A segregação é a discriminação imposta pela lei, e a dessegregação não pode fazer mais do que abolir as leis que impõem a discriminação; não pode abolir a discriminação e forçar a igualdade sobre a sociedade, mas pode e na verdade deve impor a igualdade dentro do corpo político. Pois a igualdade não só tem a sua origem no corpo político; a sua validade é claramente restrita à esfera políitica. Apenas nesse âmbito somos todos iguais. ${ }^{54}$

Arendt afirma que o princípio da igualdade não pode se pretender onipotente, não pode igualar, por exemplo, estados psicológicos, ou o modo como cada um percebe o que é o amor em uma relação conjugal. O princípio da igualdade pode e, de fato, deve promover a igualdade dentro do corpo político. Se existe preconceito ligado às formas sexuais relativas à união do mesmo sexo, a esfera política corre o ris$\mathrm{co}$, ao assumir uma apresentação condicional "afetiva" de reconhecimento das relações, de promover novas formas de discriminação. A lei quando pretende dar conta de aspectos concretos da vida dos indivíduos, por exemplo, a união conjugal, deve ser formalmente elaborada de tal modo que também dê conta das singularidades, mas valendo para todos de igual maneira. Deve estar atenta, portanto, à garantia de um direito democrático da sexualidade que atue "simultaneamente no sentido do reconhecimento do igual respeito às diversas manifestações da sexualidade e do igual acesso de todos, sem distinções, aos bens necessários para a vida em sociedade", ${ }^{55}$ coisa que a justificativa pelo amor romântico não alcança.

Nesse sentido, é importante ressaltar que o uso da homoafetividade inscreve-se nas dinâmicas de legitimação social do acesso aos direitos, características de nossa sociedade. Analisando a República Velha, Sérgio Buarque de Holanda afirma que "o desconhecimento de qualquer forma de convívio que não seja ditada por uma ética de fundo emotivo representa um aspecto da vida brasileira que raros estrangeiros chegam a penetrar com facilidade". ${ }^{56} \mathrm{Ou}$ seja, ele aponta a dificuldade de nossa cultura em utilizar um discurso impessoal que permita a ruptura com padrões particulares, como aqueles baseados nos afetos. $O$ alerta de Holanda contra a maneira como valores afetivos incidem sobre as instituições públicas é ignorado pelo clamor em torno da homoafetividade. A mobilização em torno dos afetos 
57 VECCHIATTI, 2013, p. 203.

${ }^{58}$ Disponível em: http://noticias.ter ra.com.br/brasil/cidades/scpromotor-nega-casamento-gaye-desdenha-de-noivas,e8b4888 40d80410VgnVCM4000009bcceb OaRCRD.html. Acesso em: 31 mar. 2013.

59 COMISSÃO DE DIREITOS HUMANOS E MINORIAS, 2013. é, para esse autor, um problema políico que ignora os riscos decorrentes da relativização das diferenças que separam a cena particular do mundo público.

Outro risco ao se assumir uma justificativa afetiva, particular, em detrimento a outra com validade universal, é que qualquer pessoa que, por razões próprias, não partilhe desses preceitos colocados pelo amor não estaria propensa a reconhecer o direito de união como algo válido de modo irrestrito. Nesse contexto, o amor mostra-se como uma justificativa frágil e fragmentadora. Perceba-se a forma como é defendido o reconhecimento jurídico no "direito homoafetivo": "entendo que o afeto enquanto elemento psíquico também deve ser valorizado como princípio jurídico porque em muitos casos é possível comprová-lo (por testemunhas, por exemplo)". ${ }^{57}$

A fraqueza do afeto enquanto justificativa também fica explicitada em duas situações. Recentemente, a justiça de Santa Catarina negou o pedido de casamento de duas mulheres. O promotor do Ministério Público debocha da lógica da homoafetividade da seguinte forma:

Em se tratando de situação, por óbvio, indisputavelmente anômala, posto que protagonizada por pessoas do mesmo sexo - o chamado casamento gay ou, para ser 'politicamente correto', união homoafetiva-, refugiado, assim, dos mais comezinhos parâmetros de normalidade [...]. Com clareza de fustigar a visão - a dispensar, assim, fogosos malabarismos exegéticos ou extenuantes ensaios de hermenêutica -, o ordenamento jurídico em vigor no país prestigia a união estável ou entidade familiar, sim, se composta por homem e mulher! $!^{58}$

Da mesma maneira, percebe-se essa fragilidade na negativa do projeto de lei de Maurício Rands, número 6297 de 2005, na Comissão de Direitos Humanos e Minorias da Câmera de Deputados. O projeto visava a incluir na situação jurídica de dependente, para fins previdenciários, companheiros/as homossexuais de segurados/as do INSS e companheiros/as homossexuais de servidores/as civis da União. O relator do parecer, o deputado Pastor Eurico (PSB-PE), elenca dentre as suas justificativas o seguinte:

Se considerássemos que para a dignidade da pessoa humana ser completa fosse necessário que todas as pessoas gozassem da proteção específica que o Estado dá à família, não só os homossexuais estariam preteridos, mas todos quantos mantiverem união afetiva independentemente de prática de sexo. Nesse sentido, devemos citar Platão: 'O governo da Razão deve sempre predominar sobre o instável Reino dos Sentimentos'. ${ }^{59}$

É necessária, portanto, uma justificação mais geral, que qualquer indivíduo possa reconhecer, a despeito de suas

146 Estudos Feministas, Florianópolis, 23(1): 137-150, janeiro-abril/2015 
${ }^{60}$ RIOS, 2013.

${ }^{61}$ Nancy FRASER, 2007, p. 127.

${ }^{62}$ Disponível em: http://www.esta dao.com.br/noticias/impresso,pol tica-da-ambiguidade, 948742,0 . htm. Acesso em: 31 mar. 2013. convicções, não impondo formas predeterminadas de se relacionar. Que justificativas seriam essas? Alternativas são apontadas por Rios, que aposta na concretização jurídica de novas modalidades de comunidade familiar, além das figuras do casamento e da união estável, com o acréscimo de alternativas e fundamentos ao saber e à prática do direito de família. ${ }^{60}$ Nancy Fraser, por sua vez, sugere alternativas à figura do casamento, desvinculando direitos, tais como seguro saúde, condição marital, e os prescrevendo sob outra base, tais como a cidadania ou a residência territorial. ${ }^{61}$ Já Judith Butler, analisando o contexto brasileiro e alertando para as capturas identitárias, acredita que o STF poderia ter tomado a decisão de alterar a definição jurídica de casamento para que essa não estipule o sexo das pessoas no contrato de matrimônio. ${ }^{62}$ Vemos que as soluções propostas buscam alterar as estruturas jurídicas existentes, sem apelar para argumentos que são dificilmente sustentáveis.

\section{Considerações finais}

O surgimento da homoafetividade aponta para a dificuldade na implementação de um direito democrático da sexualidade, uma vez que sexualidades não pautadas pelo amor romântico seguem política e moralmente deslegitimadas. A busca por igualdade de direitos não deve institucionalizar subjetividades, sob o risco de cair em um conservadorismo que reforça hierarquias sexuais. Longe de estar concluída, a luta por direitos para as minorias sexuais abre um precedente importante para que seja repensado o ordenamento social da sexualidade. Assim, enfatizamos, o casamento homoafetivo não é o casamento homossexual, ele é somente uma de suas formulações e não deve ser tomado como modelo universal.

A argumentação apresentada aqui buscou questionar os argumentos que sustentam a noção de homoafetividade e indicar suas fragilidades. A primeira delas diz respeito ao plano individual, pois o conceito falha em oferecer um modelo que dê conta de toda a diversidade sexual e afetiva. No plano social, falha pois reforça o preconceito que supostamente estaria ajudando a combater, assimilando modos de relacionamento entre pessoas do mesmo sexo à prevalecente norma social. Finalmente, falha no plano político, por solapar uma esfera pública universal, único lugar onde o direito democrático da sexualidade pode se concretizar.

Nossa proposição, contrária ao argumento que sustenta a ideia de homoafetividade, indica a necessidade da eleição de direitos mais elementares como justificativa para a garantia de direitos às populações LGBT brasileiras: direitos humanos de liberdade, igualdade e não-discriminação, os 
quais se desdobram em uma série de outros, inclusive no de família (afetiva ou não). Essa alternativa é mais procedente, pois se pauta em princípios que podem ser reconhecidos e aceitos, independentemente de inclinações particulares. Ao Estado cabe garantir que sejam respeitados, na medida em que sustenta uma esfera propriamente pública, laica, formal, universal e abstrata que atenda os interesses individuais sem, no entanto, estar reduzida a eles. É nesse sentido que o Estado não deve legislar sobre os afetos, apontando modelos de relações. Bastaria, portanto, justificar a necessidade do casamento civil igualitário sob princípios dos direitos elementares, sem reivindicar o amor. Uma vez garantidos esses direitos, o Estado já teria feito o seu papel de legislar, permitindo assim que cada um/a seja livre para manter o tipo de relação que desejar, mesmo que seja um bad romance.

\section{Referências}

ARENDT, Hannah. The Meaning of Love in Politics. A Letter by Hannah Arendt to James Baldwin. 1962. Disponível em: http://hannaharendt.net/documents/baldwinll.html. Acesso em: 16 jul. 2013.

"Reflexões sobre Little Rock". In: Responsa-

bilidade e julgamento. Tradução de Rosaura Einchenberg. São Paulo: Cia das Letras, 2004. p. 160-281.

AUSTIN, John. How to Do Things with Words. Cambridge: Harvard University Press, 1975.

BRASIL. Lei n. 10.406, de 10 de janeiro de 2002: institui o Novo Código Civil Brasileiro. 2002. Disponível em: http:// www.planalto.gov.br/ccivil_03/leis/2002/110406.htm. Acesso em: 10 mar. 2013

BUTLER, Judith. "Is Kinship Always Already Heterosexual?" In: $\overline{102-130}$ Undoing Gender. New York, Routledge, 2004. p.

CASTEL, Rorbert. La gestion des risques. Paris: Les Editions de Minuit, 2011.

COMISSÃO DE DIREITOS HUMANOS E MINORIAS. Projeto de Lei n. 6.297, de 2005. 2013. Disponível em: http://www.camara. gov.br/proposicoesWeb/prop_mostrarintegra?codteor $=11$ 66248\&filename = Tramitacao-PL+6297/2005. Acesso em: 31 mar. 2013.

CONRAD, Ryan. Against Equality: Queer Critiques of Gay Marriage. San Francisco: Against Equality Press, 2010.

COSTA, Angelo Brandelli; PERONI, Rodrigo; BANDEIRA, Denise; NARDI, Henrique. "Homophobia or Sexism? A Systematic Review of Prejudice against Nonheterosexual Orientation in Brazil". International Journal of Psychology, v. 48 n. 5, p. 900-909, 2013.

DIAS, Maria Berenice. União homossexual: o preconceito e a justiça. 1. ed. Porto Alegre: Livraria do Advogado, 2000.

148 Estudos Feministas, Florianópolis, 23(1): 137-150, janeiro-abril/2015 
União homoafetiva: o preconceito e a justiça. 5. ed. Porto Alegre: Livraria do Advogado, 2011.

. A família homoafetiva e seus direitos. [s.d.a]. Disponível em: http://www.mariaberenice.com.br/uploads/45__a_fam\%EDlia_homoafetiva_e_seus_direitos.pdf. Acesso em: 30 mar. 2013.

Um novo direito: direito homoafetivo. [s.d.b]. Disponível em: http://www.mariaberenice.com.br/uploads/55 um_novo_direito_-_direito_homoafetivo.pdf. Acesso em: $\overline{30}$ mar. $20 \overline{1} 3$.

D'INCAO, Maria Angela. Amor e família no Brasil. São Paulo: Contexto. 1989.

FASSIN, Didier. Humanitary Reason: A Moral History of the Present. Berkeley: University of California Press, 2012.

FOUCAULT, Michel. L'archéologie du savoir. Paris: Gallimard, 1969. . "L'éthique du souci de soi comme pratique de la liberté". In: DEFERT, Daniel; EWALD, François (Ed.). Dits et ecrits, v. IV. Paris: Gallimard, 1994a. p. 708-735. ."Entretien avec Michel Foucault". In: DEFERT, Daniel; EWALD, François (Ed.). Dits et ecrits, v. III. Paris: Gallimard, 1994b. p. 140-160. "L'éthique du souci de soi comme pratique de la liberté". In: DEFERT, Daniel; e EWALD, François (Ed.) Dits et ecrits, v. IV. Paris: Gallimard, 1994c. p. 222-243.

. História da sexualidade: a vontade de saber. Tradução de Maria Thereza da Costa Albuquerque e J. A. Guilhon Albuquerque. Rio de Janeiro: Graal, 1998.

FRASER, Nancy. Reconhecimento sem ética? Tradução de Ana Carolina Freitas Lima Ogando e Mariana Prandini Fraga Assis. Lua Nova, n. 70, p. 101-138, 2007.

HOLANDA, Sérgio Buarque de. O homem cordial. São Paulo: Penguin Classics/Companhia das Letras, 2012.

INSTITUTO BRASILEIRO DE GEOGRAFIA E ESTATÍSTICA. Censo Demográfico 2010: famílias e domicílios resultados da amostra. Rio de Janeiro: IBGE, 2012.

JØRGENSEN, Marianne; PHILLIPS, Louise. Discourse Analysis as Theory and Method. London: SAGE, 2002.

KATZ, Jonathan Ned. A invenção da heterossexualidade. Tradução de Clara Fernandes. Rio de Janeiro: Ediouro, 1996.

MASSMANN, Débora. "A homoafetividade no discurso jurídico". Revista Rua, v. 18, n. 1, p. 1413-2109, 2012. Disponível em: http://www.labeurb.unicamp.br/rua/pages/home/ capaArtigo.rua?id=123. Acesso em: 20 mar. 2013.

MCCABE, Brian; HEERWIG, Jennifer. "Reframing the Marriage Debate: Wording, Context, and Intensity of Support for Marriage and Civil Unions". International Journal of Public Opinion Research, v. 24, n. 4, p. 429-449, 2012.

MINISTÉRIO DA SAÚDE. Pesquisa de conhecimentos, atitudes e práticas na população brasileira de 15 a 64 anos, 2008. Brasília: Ministério da Saúde, 2011. 
MINUCHIN, Salvador. Famílias: funcionamento e tratamento. Porto Alegre: Artes Médicas, 1982.

PINKER, Steven. "The Game of the Name". New York Times. 1994. Disponível em: http://stevenpinker.com/files/pinker/files/ 1994_04_03_newyorktimes.pdf. Acesso em: 4 mar. 2014.

RIOS, Roger Raupp. "Para um direito democrático da sexualidade". Horizontes Antropológicos, v. 12, n. 26, p. 71-100, jul./dez. 2006.

"As uniões homossexuais e a 'família homoafetiva': o direito de família como instrumento de adaptação e conservadorismo ou a possibilidade de sua transformação e inovação". civilistica.com, v. 2, n. 2, p. 1-21, 2013.

RUBIN, Gayle. "Thinking Sex: Notes for a Radical Theory of the Politics of Sexuality". In: VANCE, Carole (Ed.). Pleasure and Danger. Boston: Routledge, 1984. p. 267-319.

SUPREMO TRIBUNAL FEDERAL. Julgamento em conjunto da $A D I$ 4227 / DF e da ADPF 132 / RJ - Rel. Min. Ayres Britto, DJe 14.10.2011. 2011. Disponível em: http://redir.stf.jus.br/ paginadorpub/paginador.jsp?docTP $=A C \& d o c I D=6286$ 35. Acesso em: 8 mar. 2014.

UZIEL, Anna Paula; MELLO, Luiz; GROSSI, Miriam. "Conjugalidades e parentalidades de gays, lésbicas e transgêneros no Brasil". Revista Estudos Feministas, v. 14, n. 2, p. 481 487, maio/ago. 2006.

VECCHIATTI, Paulo Roberto lotti. Manual da homoafetividade. São Paulo: Editora Método, 2013.

WARNER, Michael. Fear of a Queer Planet: Queer Politics and Social Theory. Minneapolis: University of Minnesota Press, 1993.

ZAMBRANO, Elizabeth. "Parentalidades 'impensáveis': pais/ mães homossexuais, travestis e transexuais". Horizontes Antropológicos, v. 12, n. 26, p. 123-147, jul./dez. 2006.

Recebido em 8 de abril de 2014. Reapresentado em 10 de setembro de 2014. Aceito para publicação em 9 de outubro de 2014.

\begin{abstract}
"Homoaffective" marriage and sexual politics: Implications of the use of Affection as Justification for Same-Sex Unions

Abstract: In Brazil, the justifications for the realization of these rights are seated in the affective aspect of the relationships between people of the same sex with the use of the term "homoaffection". The aim of this study is to critically examine this justification, pointing to its political and subjective repercussions. Foucauldian discourse analysis was used and the arguments were confronted to the debate on democratic right of sexuality in contemporary Brazilian political, and social context. The analysis indicates that the State is legislating recommending models of affection instead of guaranteeing a democratic right of sexuality, namely using romantic love discourse, even if implicitly, to produce a regulatory framework for subjectivities, based on private demands. We conclude to the need of a justification based on more fundamental rights (freedom, equality, non-discrimination) that, once secured, can ensure, a secular, formal, universal and abstract public sphere that meets the interests of individuals, including those based on romantic love, without being reduced to it
\end{abstract}

Key Words: Homoaffection; Homosexuality; Human Rights; Marriage; Civil Partnership. 